\title{
A FORMAÇÃO PROFISSIONAL E O MUNDO DO TRABALHO PELA ÓTICA DE ESTUDANTES DE CURSOS TÉCNICOS DE NÍVEL MÉDIO
}

BRUNO GAWRYSZEWSKI ${ }^{1}$

ORCID: https://orcid.org/0000-0002-7974-1711

\begin{abstract}
RESUMO: O presente texto sintetiza parte de uma pesquisa de campo que aborda as motivações, percepções e expectativas de estudantes de cursos técnicos de nível médio em questionamento sobre o processo de formação profissional e a conjuntura do mundo do trabalho. Inicialmente, o artigo contextualiza as políticas direcionadas à Educação Profissional, de modo a perceber como essa modalidade de ensino tem sido expandida desde o início do século XXI, e como tem se dado as transformações no atual cenário do mundo do trabalho. A seguir, são apresentados os resultados da pesquisa, tendo em vista a caracterização dos sujeitos participantes e suas considerações acerca do campo de análise de trabalho e educação. A interpretação das falas dos estudantes foi reveladora sobre como aspectos da subjetividade humana são dimensões desenvolvidas através das relações sociais e que essas expressões materiais representam a forma de envolvimento dos sujeitos com o mundo e como projetam suas possibilidades futuras. Por fim, são tecidas as considerações finais como síntese do texto.
\end{abstract}

Palavras-chave: Estudantes, Educação Profissional Técnica de Nível Médio, Trabalho e Educação.

\section{THE PROFESSIONAL FORMATION AND THE WORLD LABOR THROUGH THE VISION OF MEDIUM LEVEL TECHNICAL COURSE STUDENTS}

\begin{abstract}
This text synthesises part of a research that talks about the motivations, perceptions and expectations of the students in the medium level technical course about the process of the professional formation and the conjuncture of the world labor. Initially, the article discusses politics directed to professional education, in order to perceive how this teaching modality has grown since the beginning of the 21th century and has been developing the current scenario of the world labor. Later, the research results are shown considering the characterisation of the students taking part and their thoughts on field of labor and education. The judgment of the pupils statements was uncovered about how aspects of human subjectivity are dimensions changed through social relationships and that these material expressions symbolise the subjects' involvement with the world and how they project their future possibilities. Lastly, the final thoughts are woven as a synthesis of text.
\end{abstract}

Keywords: Students, Professional technical education, Labor and Education.

\footnotetext{
${ }^{1}$ Professor da Faculdade de Educação e do Programa de Pós-Graduação da Universidade Federal do Rio de Janeiro. Pesquisador do Coletivo de Estudos em Marxismo e Educação (COLEMARX). Rio de Janeiro, RJ, Brasil. <brunogawry@gmail.com>
} 


\section{FORMACIÓN PROFESIONAL Y MUNDO DEL TRABAJO DESDE LA ÓPTICA DE ESTUDIANTES DE CURSOS TÉCNICOS DE GRADO MEDIO}

RESÚMEN: Este texto resume parte de una investigación de campo que aborda las motivaciones, percepciones y expectativas de los estudiantes técnicos de secundaria en cuestión sobre el proceso de formación profesional y la coyuntura del mundo del trabajo. Inicialmente, el artículo contextualiza las políticas dirigidas a la Educación Vocacional, con el fin de comprender cómo esta modalidad de enseñanza se ha ampliado desde principios del siglo XXI y cómo ha ido cambiando en el escenario actual del mundo del trabajo. A continuación, se presentan los resultados de la investigación, considerando la caracterización de los sujetos participantes y sus consideraciones sobre el campo del análisis del trabajo y la educación. La interpretación de las declaraciones de los estudiantes fue reveladora sobre cómo los aspectos de la subjetividad humana son dimensiones desarrolladas a través de las relaciones sociales y que estas expresiones materiales representan la participación de los sujetos en el mundo y cómo proyectan sus posibilidades futuras. Finalmente, las observaciones finales se hacen como una síntesis del texto

Palabras clave: Estudiantes, Formación técnica de grado médio, Trabajo y Educación. 


\section{INTRODUÇÃO}

A Educação Profissional Técnica de Nível Médio (EPTNM), no Brasil, é atravessada por uma histórica disputa no campo educacional, no tocante a sua estrutura formativa e sistêmica dualista. No eixo analítico que trata das discussões do campo Trabalho e Educação, a educação politécnica e a escola unitária estão na base das problematizações contra a escola dual, ao considerar a centralidade da categoria trabalho e sua historicidade no modo de produção capitalista e por compreender a educação como uma unidade constituinte historicamente da formação humana, vide o legado do Grupo de Trabalho representativo do referido campo na ANPEd. A afiliação do texto ao campo Trabalho e Educação, problematiza o cimento ideológico promovido pela concepção econômica da educação, suas contradições e mediações postas pelos encaminhamentos da política educacional e diante das condições objetivas da formação social brasileira e do atual contexto político e econômico que estabeleceu mudanças significativas no mundo do trabalho (ANTUNES, 2018; ALVES, 2013). Além do mais, concebe o caráter contraditório da EPTNM em vista das determinações que implicam na dualidade do sistema educacional e na formação da força de trabalho brasileira, majoritariamente voltada para o trabalho simples.

$\mathrm{Na}$ perspectiva da classe dominante, no qual se fundamenta a concepção econômica da educação (capital humano), a EPTNM é alçada a uma condição de redentora das mazelas brasileiras, pois se ampara por pressupostos que põe em evidência "inapelável" de que a EPTNM é capaz de alavancar o desenvolvimento econômico e social do país, uma vez que "naturalmente" geraria maior produtividade aos setores econômicos e uma taxa de retorno financeiro mais rápida e compensatória àqueles que se disponham a obter tal formação.

Nesse quadro regressivo, entende-se que a premissa (e a promessa) que fundamenta a concepção econômica de educação - que estabelece uma relação causal entre ampliação dos anos de escolarização com melhora nas condições de renda e trabalho para a classe trabalhadora e desenvolvimento econômico e social do país não se confirma diante da realidade concreta. Tal premissa se mostra equivocada pois essa concepção tenta explicar a base econômica por meio de processos que a tangenciam, como a educação, por exemplo. Desse modo, a educação se torna um polo determinante para explicar o porquê de o país não atingir determinado patamar de desenvolvimento econômico. Em nosso entender, trata-se de uma inversão que busca justificar que os efeitos deletérios do parco desenvolvimento sejam explicados pela insuficiente ou inadequada qualificação da força de trabalho e não que os processos de exclusão e inclusão de trabalhadores no mercado estão organicamente vinculados ao processo de produção e reprodução do capital a partir de determinadas conjunturas históricas, conforme será evidenciada na próxima seção.

Outras determinações são postas pelas contradições da atual conjuntura histórica. No âmbito dos encaminhamentos de políticas públicas da educação, desde a década de 1990, é notória a expansão da escolarização da população brasileira e a ampliação do acesso das camadas populares em todos os níveis de escolaridade. No entanto, esse processo tem se realizado numa conjuntura que incide em expressões materiais nas relações de trabalho através da precarização, fragmentação, informalização e incertezas e que vêm afetando, sobretudo os jovens trabalhadores.

No Brasil, a EPTNM na modalidade integrada (explicação sobre as modalidades constará mais a frente) é predominantemente ofertada nas redes públicas de ensino. Trata-se de uma concepção formativa que tem obtido bastante êxito nos processos de avaliação de larga escala e de ingresso no ensino superior, sobretudo nas instituições federais. Embora o público que ocupe as vagas dessas instituições não seja exclusivamente oriunda das camadas mais pauperizadas da classe trabalhadora e que não necessariamente desejam obter a diplomação técnica para trabalhar em sua área de formação, é preciso considerar que há um significativo contingente da classe trabalhadora que ambiciona o ingresso mais imediato no mercado de trabalho e que anseia por melhores postos de ocupação laboral, em vista da qualificação especializada em determinada atividade econômica. Nesta perspectiva, a EPTNM estabelece uma encruzilhada para esses estudantes, pois, ao mesmo tempo em que essa formação técnica envolve a premente necessidade de inserção no mercado de trabalho, a depender de condições materiais e subjetivas, a inserção profissional pode retardar e até suprimir o anseio de ingresso no ensino superior. 
Portanto, a questão central posta no âmbito deste artigo é compreender como os estudantes em processo de formação profissional estão percebendo suas possibilidades futuras de ingresso no mercado de trabalho, sobretudo identificar elementos que influenciam sua escolha formativa e, consequentemente, sua trajetória escolar. Para tanto, o texto está organizado da seguinte forma: I) apresenta-se um panorama sobre as políticas relativas à educação profissional e ao mundo do trabalho; II) exposição dos resultados da pesquisa de campo em que se buscou compreender as motivações, percepções e expectativas de estudantes de EPTNM sobre a formação profissional e ingresso no mundo do trabalho; e III) as considerações finais.

Como suporte para as análises das motivações, percepções e expectativas de estudantes, foram utilizadas as contribuições de Karl Marx e Friedrich Engels e Pierre Bourdieu (cada um a seu modo) como interlocutores de que a consciência dos indivíduos está fortemente influenciada pelas relações materiais de produção e o lugar que nela os indivíduos ocupam. Acrescente-se que foram cotejados os resultados de outros pesquisadores com investigações similares no campo Trabalho e Educação e na Sociologia da Educação para a interpretação da presente pesquisa autoral.

\section{PANORAMA SOBRE AS POLÍTICAS DE EDUCAÇÃO PROFISSIONAL E MUNDO DO TRABALHO NO BRASIL: SALTAM AS CONTRADIÇÕES}

Entende-se como elucidativo que a referência à Educação Profissional se remeta ao capítulo III da Lei de Diretrizes e Bases da Educação Nacional lei no 9.394/1996 (BRASIL, 1996), denominado originalmente como "Da Educação Profissional" e depois significativamente alterado por conta da lei no 11.741/2008 (BRASIL, 2008), que conferiu novo dimensionamento para a modalidade educacional, inclusive alterando o título do capítulo para "Da Educação Profissional e Tecnológica". Basicamente, o capítulo na LDB compreende os artigos 39 a 42 e convergem diferentes níveis e modalidades de educação profissional e tecnológica ${ }^{2}$. Sua estruturação abrange cursos em três níveis de complexidade: a formação inicial e continuada, geralmente vinculada aos cursos de qualificação profissional; a Educação Profissional Técnica de Nível Médio; e a Educação Profissional Tecnológica de graduação e pós-graduação. Tais níveis de complexidade nos estudos ganharam essas nomenclaturas no Decreto no 5.154/2004 (BRASIL, 2004), conforme serão descritos abaixo.

A Educação Profissional Tecnológica de graduação e pós-graduação é oferecida somente a quem tenha concluído o ensino médio e tem normas que regulamentam a sua carga horária, objetivos e demais especificidades, a partir dos setores e áreas de atividade econômica. Já a formação inicial e continuada é oferecida em articulação com a educação de jovens e adultos e tem como objetivo a elevação da qualificação do trabalhador, embora sua certificação não confira uma titulação que lhe permita ascender na escolarização regular. Tal prerrogativa faz da formação inicial e continuada livre de regulamentação curricular por se tratar de uma modalidade educativa não-formal (CARNEIRO, 2015).

A Educação Profissional Técnica de Nível Médio (EPTNM), de que trata este artigo, pode ser oferecida por meio de três formas: integrada, concomitante e subsequente. A primeira abrange aqueles alunos que estejam com a mesma matrícula na mesma instituição, tanto no ensino médio quanto no profissional e com currículo integrado. A segunda forma trata daquele aluno que cursa ambos os níveis de ensino ao mesmo tempo, em instituições diferentes ou na mesma instituição, mas com matrícula diferente, sem integração do curso. A terceira diz respeito aos estudantes que cursam a Educação Profissional, mas já tenham concluído o ensino médio.

Os dados referentes à EPTNM evidenciam que entre 2002 e 2018 o quantitativo de matrículas mais do que triplicou. O Censo Escolar do ano de 2002, último ano de mandato do então presidente Fernando Henrique Cardoso, os cursos técnicos de nível médio atingiram 565.042 matrículas. Em 2007, início do segundo mandato de Lula da Silva na Presidência indicavam 682.431 matrículas. Já os dados referentes a 2018 informam que no Brasil constam 1.868.817 matrículas (INEP, 2003; INEP,

\footnotetext{
2 Para efeitos do presente texto, a modalidade será referida apenas como educação profissional. Educação em Revista|Belo Horizonte |v.37|e231575|2021
} 
2008; INEP, 2019), o que significa dizer que em torno de 10,6\% dos estudantes do ensino médio no Brasil estão matriculados em algum curso técnico na educação profissional ${ }^{3}$.

Por conta do quantitativo relativo que é considerado muito baixo pela Organização para a Cooperação e Desenvolvimento Econômico (segundo o relatório da OCDE, os países que integram a Organização têm média de 44\% do ensino médio), desde a década de 2000, o governo federal tem lançado iniciativas com vistas a expandir a EPTNM. No mote do lançamento em 2007 do Plano de Desenvolvimento da Educação (PDE), que preconizava iniciativas conjuntas entre os entes federativos, a Chamada Pública MEC/SETEC n. 002/2007 acolheu propostas de apoio à implementação de novas instituições federais de Educação Profissional e Tecnológica, através de parceria entre o MEC e gestores municipais. Dessa forma, os municípios receberiam uma unidade de ensino e deveriam providenciar área física para a construção da escola e demais ações que viabilizassem sua implementação, justificadas por uma estratégia de investimento que combinasse educação, desenvolvimento econômico e territorialidade. Ainda no contexto de instituição do PDE, foi lançado o programa Brasil Profissionalizado, com vistas a estimular o Ensino Médio integrado à Educação Profissional nas redes estaduais de ensino, por meio da concessão de recursos para a expansão de sua própria rede (CAIRES e OLIVEIRA, 2016).

No ano seguinte, através da Lei $n^{\circ} 11.892 / 2008$, foi estabelecida então a Rede Federal de Educação Profissional, Científica e Tecnológica que resultou na criação de 38 Institutos Federais de Educação, Ciência e Tecnologia a partir da fusão dos Centros Federais de Educação Tecnológica (CEFETs), das escolas agrotécnicas federais e das escolas técnicas vinculadas às universidades federais. A partir da construção das 150 escolas previstas na Chamada MEC/SETEC e mais 208 escolas técnicas até o fim do quadriênio 2011-2014, pretendia-se chegar a um total de 562 campi no Brasil, números esses que são imprecisos de serem constatados sua obtenção. Contudo, é certo que o orçamento para a Educação Profissional e Tecnológica foi elevado de R \$ 2,2 bilhões em 2003 para R \$ 9 bilhões em 2013 (SANTOS e RODRIGUES, 2015), o que denotou a priorização de investimento para essa modalidade de ensino.

A despeito do crescimento significativo no período temporal de 16 anos, registra-se que o ápice de matrículas na EPTNM no Brasil foi o ano de 2014, em que se registraram 1.886.167 matrículas, ou seja, justamente o final do período dos investimentos de expansão da Rede Federal. Naquele ano, foi promulgado o Plano Nacional de Educação (PNE 2014-2024) que estipulou a meta 11, meta específica para que o número de matrículas da EPTNM fosse triplicado ao final do decênio e que pelo menos 50\% (cinquenta por cento) da expansão seja ofertada no segmento público (BRASIL, 2014). Essa referida meta considera como estratégica o protagonismo dos Institutos Federais e nas redes estaduais públicas de ensino, embora também compatilize a previsão de ampliação da EPTNM através das entidades privadas do Sistema S. Sendo assim, em números absolutos, tal meta implica que, em 2024, o sistema educacional brasileiro alcance quase cinco milhões de matrículas, tendo em vista as 1.666 .138 matrículas em 2013, ano de referência para o atual PNE. A julgar pelo quantitativo de matrículas desde a vigência do PNE, a expansão vislumbrada não indica que será alcançada ${ }^{4}$.

Importante contextualizar que tais encaminhamentos políticos se deram em um contexto em que o Brasil alcançara patamar mais elevado de crescimento econômico, sendo então criados novos postos de trabalho e a maior formalização no vínculo empregatício, o que, consequentemente, gerou um crescente clamor de que a Educação Profissional fosse ainda mais expandida para sustentar um ciclo virtuoso. Nesse sentido, o marco discursivo predominante era de que, por um lado, os cursos técnicos atenderiam às aspirações dos filhos da classe trabalhadora, especialmente das camadas populares, de ter

\footnotetext{
${ }^{3}$ É preciso registrar que o relatório anual de 2018 da Organização para Cooperação e Desenvolvimento Econômico (OCDE), que é denominado Education at a Glance, informa que o Brasil, em 2016, dispunha de 9\% das matrículas de ensino médio na educação profissional (OCDE, 2018). No entanto, o quantitativo informado não condiz sequer com os números oficiais informados pelo Estado brasileiro, tendo em vista que, em 2016, foi registrado um total de 8.133 .040 matrículas e que, dentre essas, 531.843 eram da modalidade integrada e 329.033 da modalidade concomitante, o que perfaz um total de 860.876 matrículas (INEP, 2019). Não é possível apontar se a origem do erro foi do Estado brasileiro ou da organização internacional, mas há um equívoco.

${ }^{4}$ A outra meta que se refere diretamente à Educação Profissional é a meta 10, que define oferecer pelo menos $25 \%$ das matrículas de Educação de Jovens e Adultos integrada à Educação Profissional. Nos últimos anos, as matrículas integradas tiveram o ápice em 2015, com 3\% e, desde então, diminuiu para metade do quantitativo proporcional (BRASIL, 2018). 
acesso a uma formação mais qualificada e que os colocasse em melhores condições para vender sua força de trabalho. Por outro, também atenderia as demandas do empresariado, que propagou discurso de que estaria ocorrendo no Brasil um "apagão de mão de obra", o que, do ponto de vista das empresas, teria criado dificuldades para contratar força de trabalho qualificada para ocupar os cargos disponíveis.

Nessa conjuntura, por iniciativa do governo federal, a Lei $\mathrm{n}^{\circ} 12.513 / 2011$ instituiu o Pronatec (Programa Nacional de Acesso ao Ensino Técnico e Emprego) como uma tentativa de adensar à expansão da própria Rede. Outras iniciativas também compuseram essa política, como a oferta de bolsas de estudo a estudantes e trabalhadores (Bolsa Formação), o financiamento para entidades privadas de ensino (Fies técnico/Fies empresa), acordo de gratuidade com o Sistema $\mathrm{S}$, o apoio à expansão das redes estaduais de educação profissional e o ensino a distância (e-Tec), todas elas coordenadas pela Secretaria de Educação Profissional e Tecnológica do Ministério da Educação (CASSIOLATO e GARCIA, 2014).

O Pronatec, apesar de prever um adensamento à expansão da própria Rede Federal, priorizou a oferta de bolsas de estudo para estudantes e trabalhadores em instituições privadas de ensino. Entre 2011 e 2014, o Pronatec alcançou oito milhões de matrículas, sob condição de $92 \%$ dos recursos utilizados na ação orçamentária 20RW (apoio à formação profissional, científica e tecnológica) foram destinados ao Sistema $\mathrm{S}^{5}$, o que totalizou um montante de $\mathrm{R} \$ 5,88$ bilhões para essa organização empresarial (COSTA, 2015), constatação reiterada por Motta e Frigotto (2017), que chegaram a números semelhantes. Outra asseveração em relação ao programa foi que, entre 2011 e 2014, o Pronatec ao alcançar a meta inicialmente estipulada de 8 milhões de matrículas, o fez com a proporção de 2,3 milhões (28\%) em cursos de EPTNM (mínimo de 800 horas) e 5,8 milhões (72\%) em cursos Formação Inicial e Continuada (FIC - em média, cursos de 160 horas). Esses dados evidenciam a fragilidade do discurso que pressupõe um nexo causal entre educação e desenvolvimento econômico, já que a maior parte das matrículas no Programa se destinou a cursos aligeirados e de formação simples, com baixo valor agregado.

Sob o mandato presidencial de Michel Temer, a partir de maio de 2016, o governo federal anunciou duas medidas de reestruturação do Pronatec: o plano Progredir, que consistiu na oferta de cursos a distância de qualificação profissional com duração de 160 horas, sob pretexto de rápida inserção no mercado de trabalho e abertura de seu próprio empreendimento; e a criação do MedioTec, como uma ação suplementar do supracitado programa, que seria repassado às instituições de ensino um valor para cobrir os custos com a formação do estudante na EPTNM. O público-alvo se destinava à população considerada "socialmente vulnerável" e beneficiários do programa Bolsa Família. Em ambos os casos, é possível afirmar que os programas tiveram incidência irrelevante, sobretudo em comparação às ações executadas pelos governos petistas de Lula e Dilma.

Por fim, em relação às iniciativas que tangem à EPTNM, mas não menos importante em nível nacional, a promulgação da lei 13.415/2017, que instituiu uma reforma no Ensino Médio. Esta instaura uma proposta de reorganização dessa etapa de ensino, na qual é definido um limite de $1.800 \mathrm{~h}$ de base comum aos conteúdos curriculares (máximo de 60\% da carga horária para um total mínimo de 3.000 horas), e, posteriormente, os estudantes deverão optar por itinerários formativos disponíveis, dentre os quais um deles é a formação técnico-profissional. Essa reforma na organização e fundamentação para o ensino médio ainda caminha no sentido de expedir maiores regulamentações e definições sobre sua implementação, por isso não será aprofundada no presente artigo. Entretanto, considero importante indicar que essa reforma traz à tona a reivindicação da classe dominante de formar trabalhadores adequados às atuais condições do mundo do trabalho - caracterizadas pela precarização e pela intensificação da exploração da força de trabalho -, de modo a desenvolver nos jovens as habilidades para a vida, sobretudo para tomar "boas decisões" acerca do seu projeto de vida em um mundo marcado por instabilidades e incertezas (MOTTA; LEHER; GAWRYSZEWSKI, 2018). Trata-se de uma proposta formativa que se distancia de todo acúmulo histórico construído pelo GT Trabalho e Educação da ANPEd em favor do ensino médio integrado à formação profissional, que tem como proposição

\footnotetext{
${ }^{5}$ Designação feita ao conjunto das instituições que compõem as entidades vinculadas aos serviços prestados na formação e qualificação profissional e atividades sociais e recreativas de cada segmento econômico brasileiro. As respectivas instituições estão vinculadas à Confederação Nacional da Agricultura e Pecuária do Brasil, Confederação Nacional do Comércio, Confederação Nacional da Indústria, Confederação Nacional do Transporte e Sistema Cooperativista Nacional. Educação em Revista|Belo Horizonte|v.37|e231575|2021
} 
principal a integração curricular em torno do eixo ciência, cultura, trabalho e tecnologia, e que possui como fundamento o princípio educativo do trabalho.

Pode-se afirmar que as ações destinadas à EPTNM induzem, ainda que de forma breve, a uma reflexão sobre os processos produtivos na contemporaneidade. Conforme demonstrado, houve uma expansão significativa da EPTNM nos últimos 15 anos, em que tal expansão foi justificada para atender a uma suposta necessidade do empresariado de formar estoques de força de trabalho mais qualificada para (a fim de) aumentar o potencial de produtividade das empresas. No entanto, embora a escolaridade em nível médio e superior tenha tido relativo crescimento na primeira década do século XXI, Deitos e Lara (2016, p. 177) consideram que "Contraditoriamente, o processo de produção requer níveis de qualificação por ocupação que, de forma relativa, movem-se em desencontro com os níveis de escolarização requeridos pelos setores econômicos". Os dados compilados pelos autores referentes à Pesquisa Nacional por Amostra de Domicílios (PNAD) entre 2002 e 2011 revelaram que os requisitos para ocupação por nível de escolarização pouco se alteraram, predominando o nível baixo e médio de qualificação (79\%). A síntese dos dados apresentados pelos autores acima fornece elementos para concluirmos que há um descompasso entre o discurso do empresariado em relação ao "apagão de mão de obra qualificada" e as opções de fato de contratação e/ou ocupação do trabalhador brasileiro pelo empresariado. Tal conclusão talvez explique que a maior ênfase na oferta de cursos FIC do Pronatec possa estar relacionada tanto à captação de recursos públicos providos pelas instituições do Sistema $\mathrm{S}$, como à própria demanda efetiva de força de trabalho no Brasil.

É importante atentar para o fato de que na atual conjuntura político-econômica, de acumulação flexível sob a égide do neoliberalismo, a estrutura produtiva foi alterada, tornando-se mais flexível, com postos de trabalho reduzidos e em consequência a precarização do trabalho foi intensificada. Como demonstram as pesquisas de Alves (2013) e Antunes (2018), entre outros, elementos combinados do padrão de organização fordista e da acumulação flexível, produção por demanda em empresas enxutas, salários vinculados à produtividade e a intensificação das novas tecnologias têm potencializado processos de precarização nas relações de trabalho. Nesse sentido, o acirramento da competividade no mercado internacional tem colocado de forma permanente a pauta da Reforma Trabalhista por parte do empresariado, a fim de reduzir ainda mais os custos da força de trabalho; o que incide em mais perdas de direitos trabalhistas. O próprio presidente Jair Bolsonaro, ao comentar que, diante de tantos direitos previstos ao trabalhador, "[...] os empreendedores contratam o mínimo possível e pagam o mínimo possível", por isso, os trabalhadores deveriam optar por "menos direito e mais emprego ou todos os direitos e o desemprego" (BOLSONARO, 2019), dá o tom do que seria o motor do crescimento do capitalismo brasileiro: a expropriação de direitos e superexploração da força de trabalho. Fontes (2010) compreende que a expressão atual das expropriações dos direitos faz parte de um processo histórico em que novas formas de extração de mais-valor serão introduzidas através da captura de recursos de origem salarial, a fim de transformá-los em capital.

Não à toa tem ocorrido um sistemático investimento de propagação de reportagens e entrevistas com "especialistas" na grande imprensa para justificar as reformas, além da disseminação de materiais por meio de redes sociais (inclusive apelando para fatos e argumentos que ferem qualquer princípio de racionalidade) e a realização de eventos acadêmicos e publicações editoriais que tem finalidades muito bem definidas. Pode-se dizer que se trata de um movimento que combina discursos com caráter de convencimento coercitivo ("não haverá dinheiro para pagar a aposentadoria das próximas gerações") e coerção consentida ("inevitavelmente mais mortes ocorrerão"), a fim de legitimar aos trabalhadores as ações dos governos contra os próprios trabalhadores (a coerção concretizada). A esse movimento, Fontes (2010, p.55) compreende que:

Tratou-se de introduzir uma nova "normalidade": segmentar cada situação ou direito tornado alvo prioritário e deter-se nela exaustivamente, por todos os meios midiáticos. O plano internacional era sempre apresentado como modelar, tanto para o melhor (o bom exemplo), quanto para o pior (a tragédia). 
Por isso, a pauta da Reforma Trabalhista, na busca por "modernizar e flexibilizar" as relações entre patrões e empregados, frequentemente referencia-se em exemplos dos países do capitalismo central que já aprovaram modificações legislativas nesse sentido (especialmente, nesse caso, países europeus) ou que já não dispunham mesmo de larga proteção social e de combatividade por parte dos sindicatos (casos de Estados Unidos, China, Japão e asiáticos, de modo geral). A promessa, portanto, é de que seguindo pelo mesmo caminho (a despeito de desconsiderar contextos histórico-sociais), o Brasil teria condições de alavancar o crescimento econômico e retomar a contratação de trabalhadores. Sob essa justificativa, em 2017, duas legislações que compunham a pauta trabalhista foram aprovadas: a lei no 13.429/2017, conhecida como Lei da Terceirização; e a lei no 13.467/2017, denominada como Reforma Trabalhista. Resumidamente, a primeira permite a universalização da terceirização, antes restrita apenas às ocupações consideradas como meio e não como fim da atividade de determinada empresa (por exemplo, um docente em relação à uma escola); a segunda, é mais abrangente e modifica diversos dispositivos previstos pela Consolidação das Leis do Trabalho, mas, que pode ser sintetizado na premissa de que os acordos individuais ou coletivos possam prevalecer sobre o conteúdo previsto em lei, por isso, a qualificação como flexível . Não sendo objetivo examinar o conteúdo das legislações supracitadas, o fundamental é que elas expressam a concepção de mundo da classe dominante, ainda que por meio de prepostos diretos ou disseminado como senso comum pela classe trabalhadora, a mais vulnerável aos efeitos da nova "morfologia do trabalho no Brasil" (ANTUNES, 2018).

A consequência do processo de precarização das relações de trabalho no Brasil, além de não produzir os resultados prometidos pelas ações de reforma trabalhista, tem afetado de sobremaneira os jovens. A PNAD/IBGE do segundo trimestre de 2019 constatou que a taxa de desocupação da população entre 18 e 24 anos está em $25,8 \%$, ou seja, mais do que o dobro dos $12 \%$ da média total (IBGE, 2019), patamar que tem se mantido superior a 25\% há pelo menos quatro anos.

O avolumamento de jovens que não estão em situação de ocupação laboral, somado àqueles que por desalento sequer procuram trabalho e também interrompem seus estudos, tem sido classificado como os jovens nem-nem, pois estes estariam numa condição de indeterminação sobre suas próprias vidas, já que ao mesmo tempo estariam fora do sistema de ensino e de qualquer garantia de formalidade no mercado de trabalho. A muitos desses jovens (embora também os adultos maduros e idosos) a alternativa que tem se apresentado como opção imediata são as ocupações vinculadas a serviços por aplicativos. Ainda não há um rol de pesquisas acadêmicas consistentes sobre essa recentíssima condição de trabalho, mas se estima que em torno de quatro milhões de pessoas tem se dedicado a serviços por aplicativos. De modo geral, as empresas que prestam os serviços por aplicativos se apresentam como intermediários entre consumidores e fornecedores por meio de trabalhadores autônomos que livremente se associam à empresa, aceitando as condições das plataformas digitais. A esse novo estágio das relações trabalhistas tem se atribuído o nome de "uberização do trabalho", pois aprofunda o modelo de terceirização e subcontratação, na medida em que o trabalhador passa a ser uma espécie de "nanoempresário-de-si permanente disponível ao trabalho" (ABÍLIO, 2017, s/p).

Portanto, diante de um cenário não muito promissor no mundo do trabalho, mas de expansão das possibilidades via escolarização (ainda que demonstrado que o poder público não necessariamente priorize um nível de formação mais robusto), compreender de que maneira os estudantes de EPTNM baseiam suas motivações, percepções e expectativas sobre sua possível inserção no mundo do trabalho e a formação profissional recebida por meio do curso técnico é o objetivo da próxima seção.

\section{MOTIVAÇÕES, PERCEPÇÕES E EXPECTATIVAS DOS ESTUDANTES DA EPTNM}

Traçado o perfil da EPTNM no Brasil, as políticas públicas realizadas e em curso nos últimos 20 anos, bem como analisadas as determinações e as contradições postas pela conjuntura política no mundo do trabalho, almejo nessa seção expor como as motivações dos estudantes da EPTNM, bem como estão percebendo seu processo formativo profissional e construindo expectativas futuras através da realização de pesquisa de campo. Nesse sentido, a corrente seção está organizada de modo a: I) 
exposição dos procedimentos metodológicos; II) identificação dos sujeitos participantes; III) resultados da pesquisa através dos grupos focais.

\section{Procedimentos metodológicos}

A pesquisa de campo foi desenvolvida entre o segundo semestre de 2017 e o primeiro semestre de 2018. No total, foram visitados sete cursos técnicos de nível médio, todos mantidos por instituições de ensino públicas, sendo duas delas vinculada à esfera de governo estadual e as demais, federal. Entre os cursos, seis deles pertenciam à modalidade integrada, e um, no turno noturno, da modalidade subsequente. Frisa-se que, pelo fato de a pesquisa acarretar interação direta com seres humanos, o projeto foi submetido e aprovado por um comitê de ética em pesquisa na Plataforma Brasil através do parecer sob o no 2.224.740, em junho de 2017. De acordo com o que foi pactuado com os sujeitos entrevistados, todas serão mantidas em anonimato, bem como as respectivas instituições, já que essa identificação não acarreta ganhos qualitativos para o desenvolvimento da pesquisa.

Ao final de todas as visitas, houve contato direto com 115 estudantes. O critério de seleção do universo de pesquisa era que eles tivessem concluído ao menos $50 \%$ do respectivo curso, de modo a estarem em uma condição mais favorável a emitir julgamentos sobre a formação da instituição de ensino e inclusive alguns deles já tinham participado ou estavam participando de estágios em empresas. Primeiramente, esses estudantes foram convidados a responder um questionário que caracterizasse o seu perfil socioeconômico e familiar e sobre das motivações, percepções e expectativas de estudantes de EPTNM acerca de aspectos referentes tanto ao mundo do trabalho quanto à formação profissional, o cerne do presente texto. Àqueles que sinalizassem positivamente no questionário, alguns desses foram convidados a participar de uma sessão de entrevista coletiva, através da técnica de pesquisa denominada como grupo focal, o que foi realizado em apenas quatro dos sete cursos, seja por conta de falta de interesse dos estudantes ou por inviabilidade do procedimento por conta do calendário acadêmico da instituição.

A técnica de pesquisa de grupo focal tem como premissa a organização de um grupo de discussão a fim de dialogar sobre um tema em particular após receberem estímulos pertinentes a essa finalidade. Espera-se que haja um processo de interação entre o grupo sobre um assunto de interesse comum entre os participantes. $\mathrm{Na}$ medida em que transcorra a dinâmica, trata-se de uma oportunidade para exposição e confronto de crenças, valores e conhecimentos. Para isso, o pesquisador em questão, ao conduzir a dinâmica, realiza uma ação para tornar cognoscível o objeto pesquisado, independentemente de sua própria crença, o que implica que a finalidade no grupo focal seja, segundo Gomes (2005, p. 279) "[...] extrair das atitudes e respostas dos participantes do grupo sentimentos, opiniões e reações que resultariam em um novo conhecimento".

No caso do presente artigo, as sessões de grupo ocorreram nas respectivas instituições de ensino e em cada uma das quatro sessões realizadas, contou-se com a presença do pesquisador responsável e de uma a dois pesquisadores assistentes. Realizadas e transcritas as entrevistas, passou-se à fase de análise, em que o esforço foi o de identificar tendências e relações nas respostas. Desse modo, foram organizados em cada resposta, os tópicos e palavras-chave mais acionados pelos sujeitos entrevistados, o que permitiu agrupar esses fragmentos das falas para, assim, determinar relações entre os temas abordados e construir uma interpretação concernente à finalidade da pesquisa.

\section{Identificação dos sujeitos}

Conforme já explicitado na seção anterior, ocorreu contato 115 estudantes de EPTNM, os quais responderam inicialmente a um questionário de duas páginas. A primeira se estruturou em torno de um questionário que caracterizava o perfil socioeconômico e familiar. Na página seguinte, as perguntas versavam sobre a compreensão das motivações, percepções e expectativas de estudantes de EPTNM acerca de aspectos referentes tanto ao mundo do trabalho quanto à formação profissional. Apresenta-se abaixo, sinteticamente, a estruturação do questionário, no quadro a seguir: 
Quadro 1 - Temas contemplados no questionário e explorados nos grupos focais

\begin{tabular}{|c|c|c|}
\hline \multirow{4}{*}{$\begin{array}{l}\text { Perfil estudantes } \\
\text { EPTNM }\end{array}$} & Caracterização social & $\begin{array}{ll}\text { 1. } & \text { Idade } \\
\text { 2. } & \text { Sexo } \\
\text { 3. } & \text { Estado civil } \\
\text { 4. } & \text { Autodeclaração cor/raça } \\
\text { 5. } & \text { Escolaridade e ocupação de pais e mães }\end{array}$ \\
\hline & Caracterização econômica & $\begin{array}{l}\text { 1. Renda familiar } \\
\text { 2. Relação com mundo do trabalho }\end{array}$ \\
\hline & $\begin{array}{l}\text { Motivações, percepções } \\
\text { expectativas educacionais }\end{array}$ & $\begin{array}{ll}\text { 1. } & \text { Motivação com EPTNM } \\
\text { 2. Expectativa familiar } \\
\text { 3. Expectativas de futuro } \\
\text { 4. } \\
\text { Percepções sobre a formação escolar }\end{array}$ \\
\hline & $\begin{array}{l}\text { Motivações, percepções } \\
\text { expectativas laborais }\end{array}$ & $\begin{array}{l}\text { 1. Percepção curso e demandas do mercado } \\
\text { 2. Percepção sobre emprego e relações } \\
\text { trabalhistas } \\
\text { 3. Expectativa de insercão no mundo do trabalho }\end{array}$ \\
\hline
\end{tabular}

Para efeitos de exposição no presente texto, a caracterização socioeconômica e familiar será realizada com base nos questionários e as motivações, percepções e expectativas educacionais e laborais, a partir da realização dos grupos focais, já que puderam ser mais desenvolvidos nessa dinâmica.

O levantamento específico da pesquisa desenvolvida pela autoria do presente texto indicou que $68(59 \%)$ respondentes se identificaram como sexo masculino. Com relação à faixa etária, dois terços eram estudantes com faixa etária entre 16 e 18 anos, o que nos parece explicar que 107 se declarem como solteiros, 108 não tenham filhos e 105 morem com parentes.

Em relação à autodeclaração de cor/raça, $50(43,5 \%)$ os respondentes se identificaram como pessoas de cor/raça branca, $26(22,6 \%)$ como parda e 29 (25,2\%) como negra. Nesse caso, o quantitativo de pessoas que se identificam como negros e negras é bastante superior ao universo da Educação Profissional mensurado pelo Censo Escolar no estado fluminense, que aponta que em torno de 6\% pouco mais de 10 mil estudantes dentre o universo total de 170.870 - se declaram como tal (INEP, 2019). Por não se tratar de objetivo imediato da pesquisa, não será explorado tal achado, mas indico a pertinência de compreender os fatores que possam influenciar o resultado nessas escolas de EPTNM pertencentes à rede estadual e federal de ensino.

No que diz respeito ao grau de escolarização, ocupação e renda dos pais e mães da presente pesquisa, embora tenham sido respondidos tais perguntas, no movimento de avaliação das respostas, foi concluído que a diagramação e formatação do questionário não favoreceu a uma resposta segura e confiável por parte dos estudantes nesses itens, sobretudo porque se remete a pessoas que não os próprios sujeitos respondentes e a perguntas que nem sempre o público se sente confortável a responder, como a questão da renda familiar. Por conta disso, optou-se por descartar a exposição desses dados, embora tenha optado por informar que tais dados não foram ignorados no momento de realização da pesquisa.

Quando instados a responder sobre sua relação com o mundo do trabalho, 62 responderam que ainda não tinham qualquer experiência laboral, mas que 45, ou seja, quase metade do universo da pesquisa, já exerciam ou exerceram em algum momento uma ocupação, apesar de, no momento da pesquisa, apenas 26 declararem que estavam exercendo alguma atividade laboral. As ocupações mais citadas pelos estudantes foram as de estagiários (9) e igual quantitativo (9) de monitores e bolsistas. Possivelmente isso se deve às características das instituições de ensino pesquisadas, que promovem esse tipo de formação acadêmico-profissional ao seu alunado. Entre os que declaram ter experiência com o mundo do trabalho, 19 deles iniciaram suas atividades antes dos 18 anos, mas conforme destacado acima, uma significativa parcela em funções relacionadas à própria formação profissional, embora haja pequena amostra que tenha declarado ter exercido ocupações de baixa qualificação, como motoboy, pintor e telemarketing. Nesse sentido, esse achado se diferencia, por exemplo, da pesquisa de Marcassa e Conde (2017) que investigaram jovens estudantes, em sua maioria do ensino médio, em território de precariedade social em Florianópolis. As pesquisadoras mostraram que, para os seus interlocutores, o trabalho era uma realidade para quase $70 \%$ deles e que um terço começou a trabalhar antes dos 16 anos e que suas 
ocupações são predominantemente informais de vínculos trabalhistas ou em funções de baixa qualificação como lavador de carro, assistentes para serviços gerais, balconistas, garçons ou entregadores para bares e restaurantes e telemarketing em jornadas de trabalho que eventualmente superam quarenta horas semanais.

\section{Os grupos focais}

A partir daqui, serão exploradas as questões relacionadas às motivações, percepções e expectativas educacionais e laborais dos estudantes do EPTNM. As sessões realizadas tinham um roteiro previamente pensado, mas em função da manifestação dos entrevistados, a ordem e a ênfase para cada tema seguiam o fluxo da própria discussão. Entretanto, em todas as sessões o debate foi iniciado com a pergunta sobre a motivação e fatores que os levaram a escolherem os respectivos cursos. Decerto, além de algum grau de identificação com o curso, outros fatores foram bem mais enfatizados do que o próprio gosto pessoal, como a influência e/ou imposição dos pais e mães.

Desde pequena a minha mãe ela tem muita condução, sabe, nas escolhas que eu faço relacionado
a tudo da vida, não foi diferente com a questão de ensino e estudo. Eu sempre fui muito
orientada e tudo mais, quando eu fui crescendo e vendo a importância que tinha tudo eu já
comecei a conversar com ela sobre a questão de carreira [...] A minha mãe, ela fez técnico em
eletrônica e seria essa a minha opção, mas acabei estudando um pouco a área e vi que não era
muito a minha cara, não era algo que me encantava e eu iria acabar fazendo pelo fato que ela fez.
Então a gente junta, e eu decidi ir para edificações (Estudante escola A).

Eu escolhi porque meu pai falou que eu tinha que fazer um curso técnico pra quando terminasse o meu ensino médio pra ter, de certa forma, um emprego garantido (Estudante escola C).

Eu escolhi por indicação. Eu tenho uma pessoa da minha família que faz o curso e que gostava, então eu decidi fazer (Estudante escola C).

Conforme foi possível constatar com as falas, a família tem um peso significativo em mobilizar que os jovens escolham uma instituição pública de ensino técnico para cursar o ensino médio. Essa mobilização escolar familiar é entendida por Nogueira, Resende e Viana (2015, p. 763), em uma perspectiva sociológica, como "[...] um conjunto de práticas e atitudes voltadas para a escolarização bemsucedida dos filhos". A preocupação das famílias em escolher uma "boa escola" para os filhos cursarem o Ensino Médio, portanto, pode estar associada à experiência ou conhecimentos dos pais ou familiares que visualizam na instituição uma "referência de qualidade" para abrir leque mais sortido de oportunidades tanto de estudo quanto de trabalho. Por isso, há uma notória vinculação entre a reputação da instituição e uma suposta condição favorável para desfrutar de oportunidades melhores no mundo do trabalho.

O colégio abre bastante porta pro médio e pro técnico (Estudante escola C)

Além do que, o (nome da instituição) tem nome, né? Acaba estudando num colégio federal, que tem tradição, que tem renome, então você já pega um diferencial. [Um estudante o interrompe: A empresa já te olha com outros olhos. Eles costumam aceitar, tá mais aberto ao pessoal do (nome da instituição)] (Estudante escola C).

É possível então interpretar que a influência para escolha do destino dos estudantes por parte dos familiares, ainda que possa se relacionar em alguma medida com suas "vontades e aptidões" de seus filhos, tomam uma forma material através das experiências que os indivíduos adquirem a partir das condições objetivas em que se encontram. Por isso, Pierre Bourdieu critica asperamente o termo "vontade dos pais" como fator explicativo da escolha do destino e da formação dos estudantes, pois este termo negligencia as relações concretas que conferem materialidade às escolhas dos indivíduos.

As atitudes dos membros das diferentes classes sociais, pais ou crianças e, muito particularmente, as atitudes a respeito da escola, da cultura escolar e do futuro oferecido pelos estudos 
são, em grande parte, a expressão do sistema de valores implícitos ou explícitos que eles devem à sua posição social (BOURDIEU, 2015, p. 51).

Ao segmentar as escolhas e destinos entre as classes sociais, Bourdieu traz à tona um ideal ascético de ascensão social por parte das famílias de classe média, as quais devotam todo tipo de esforço e encorajamento para obtenção do êxito escolar e profissional de seus filhos, ao passo que a classe trabalhadora, tendo em vista suas privações materiais, ajusta seu nível de aspiração a partir de suas possibilidades de recompensa, por conta da

[...] interiorização do destino objetivamente determinado (e medido em termos de probabilidades estatísticas) para o conjunto da categoria social à qual pertencem. Esse destino é continuamente lembrado pela experiência direta ou mediata e pela estatística intuitiva das derrotas ou dos êxitos parciais das crianças do seu meio [...] (BOURDIEU, 2015, p.52).

Outro sentido que foi explorado junto aos estudantes foi como percebem a relação entre a formação recebida na instituição de ensino e a aderência às ditas "demandas do mercado de trabalho". As falas destacadas dão a tônica que os estudantes têm uma percepção de que embora reconheçam que seus respectivos cursos lhes confiram uma base de conhecimentos, atendem somente parcialmente a uma formação que lhes possa capacitar o ingresso profissional, sobretudo, pela distância entre aspectos que simulassem de modo mais realista o exercício profissional.

Bem alinhado mesmo, completamente satisfatório (Estudante escola A)

Eu acho que o curso poderia ser atualizado tanto na questão dos professores quanto no ementário dele. Acho que é o que a (outra aluna) falou, eu acho que ele dá uma base mas a gente sai zerado daqui [...] Eu acho que as coisas têm que acompanhar as demandas do mercado, essa questão sobre a construção sustentável e gente não tem nada sobre isso. A gente não tem nenhum tipo de palestra, a gente não tem nenhum tipo de visita técnica assim como ela falou (Estudante escola B).

Eu acho que a gente tem uma base maneira, tem coisas legais, mas falta uma refinada (Estudante escola C)

Eu já escuto de algumas pessoas que: "Ah, no Senai, o pessoal mecânico é melhor; aqui vocês são profissionais melhores." Não desmerecendo trocar, a pessoa sabe a peça A ou peça B, aqui a gente sabe como funciona a peça A e a peça B (Estudante escola C).

Achei que fosse viajar [risos]

Eu queria viajar e pensei que teria mais línguas (Duas estudantes escola D)

Ao dissertarem sobre a conjuntura do mundo do trabalho, unanimemente os estudantes têm a percepção de que vivem em tempo histórico de difícil inserção em empregos formais e precarização das relações trabalhistas. No entanto, suas falas revelam uma heterogeneidade quanto à forma de lidar com a situação. Enquanto a maioria salienta a dificuldade da atual configuração no mundo do trabalho, a percepção da estudante da escola $\mathrm{A}$ entende que a conjuntura de crise favoreceria a contratação de técnicos, justamente por estarem em patamar abaixo da divisão social do trabalho, o que demandaria menor investimento com a força de trabalho.

Em época de crise, o empresário não dispõe de tantos recursos assim ou até dispõe, mas ele não quer aplicar seus recursos contratando esse tipo de profissional [com nível superior]. Ele quer alguém que atenda a demanda dele ali, a um preço mais acessível e o técnico é isso. O técnico ele tem grande noção daquilo ali, cerca de $80 \%$ a $90 \%$, a um preço reduzido (Estudante escola A)

A nossa área não está no auge. Aqui a nossa turma, a gente antes de procurar em oficinas médias, a gente procura em concessionárias, em lugares maiores e realmente a gente viu que está difícil. Tem vezes que a gente nem passa da porta de entrada (Estudante escola C)

Educação em Revista|Belo Horizonte|v.37|e231575|2021 
O pessoal tá buscando muito estágio na área de manutenção porque é a que mais tá contratando, mas [...] na minha opinião, tá um pouco complicado o mercado (Estudante escola C)

Ninguém tá se dando bem, aí ninguém tá tirando tempo para viajar, aí ninguém está contratando a gente (Estudante escola D)

Também foi abordado o sentido de projeção de vida nos estudantes de EPTNM, ou seja, algo que o indivíduo se proponha a realizar em alguma dimensão de sua vida. Contudo, considerando que majoritariamente o universo da pesquisa tem como interlocutores adolescentes e jovens adultos, tais projetos vão se transformando na medida do próprio amadurecimento e descoberta dos indivíduos. Possivelmente diversos projetos nascem, enquanto outros morrem ou são colocados de lado perante as situações do tempo presente que vão conformando as aspirações em níveis de possibilidades concretas de realização ou não. Fundamentalmente, trata-se de uma relação do projeto de vida com o tempo, sobretudo em relação ao futuro que se torna fruto de um devir que "[...] aparece ligado por um duplo fio, as escolhas e as decisões do presente” (LEÃO; DAYRELL; REIS, 2011, p. 1072). Tal premissa pode ser percebida, por exemplo, na pesquisa de Correa e Cunha (2018) com jovens do ensino médio da rede estadual de ensino de Minas Gerais, quando, instados a se expressarem sobre como são desafiados a analisarem e tomarem decisões que venham a ter algum impacto em seu futuro, um dos jovens disse:

[...] o que eu quero fazer? Eu decidi o que eu não quero fazer mais, mas eu não sei o que que eu quero fazer agora. E começa toda a preparação de ENEM, de... olhar a faculdade que vai ser apta para mim, lugares que... vão recorrer nisso, se vou para uma escola interna, se vou ficar indo em casa mesmo na faculdade com campus, sem campus, é... o que que eu tô fazendo... E se eu começar a trabalhar, como é que eu vou conciliar isso e escola... então tem toda uma preparação que você tem que se preparar, mas ao mesmo tempo você... cê não sabe por onde começar isso. (CORREA; CUNHA, 2018, p. 14-15)

$\mathrm{Na}$ pesquisa executada de autoria no presente texto, as seguidas falas dos estudantes apresentaram possibilidades e análises diversas.

Eu acho difícil falar em projeção já que o Brasil está em crise [...] na atual situação eu não tenho muitas expectativas, eu tento mudar o rumo dos meus pensamentos e focar em outras coisas que talvez sejam mais interessantes (Estudante escola B).

Eu gosto de trabalhar na oficina que eu já fiz estágio e eu gosto, mas não quero isso pra minha vida toda [...] Então é meio que assim, um curso técnico em geral, é meio que um limbo entre a escola e a faculdade porque muita coisa que a gente aprende aqui, não vai aprender lá fora (Estudante escola C).

No meu caso, o curso técnico como técnico é uma área que quero seguir, quero viver e trabalhar numa oficina, um dia eu até quero ter a minha oficina (Estudante escola C).

Eu vi o técnico como uma maneira de me descobrir, uma abertura pra algo que eu quero mais pra frente, também quero cursar engenharia, como a maioria aqui, mas a área específica da engenharia, o meu curso de Manutenção Automotiva, me fez ver qual área que quero seguir (Estudante escola C).

Se eu pudesse escolher sem preocupação nenhuma, a melhor parte seria virar blogueira (Estudante escola D).

Conforme foi possível constatar em falas dos estudantes, não há homogeneidade nas aspirações de projeto de vida, embora a relação com o tempo futuro esteja presente. A estudante da escola B foi a mais pessimista, pois considerou que a conjuntura econômica do país seria um fator que limitaria suas expectativas de projeção futura, conformando sua vida (naquele momento) a uma condição de suspensão de planos. Com relação aos estudantes da escola C, estes demonstraram satisfação com o curso técnico e a possibilidade que este lhe oferece como horizonte profissional. Por último, a estudante da escola D, refletindo uma certa frustração pela incapacidade do seu curso em proporcionar mais 
experiências relacionadas com a formação profissional, projeta um certo imaginário para uma realidade para além da sua, porque, fatalmente, ela seria ao menos mais prazerosa do que a vivida . Nessa amostra de respostas, pode-se constatar que, não necessariamente o curso técnico aparece como uma terminalidade profissional para todos, mesmo que reconheçam a qualidade de sua formação.

Complementando os trechos anteriores, foi possível perceber que, apesar de alguns estudantes demonstrarem pessimismo ou certa incredulidade por conta da crise econômica, amplamente divulgada pelos canais de comunicação, diversos deles atribuem a si mesmos a responsabilidade pela inserção no mundo de trabalho, utilizando um discurso voltado ao desenvolvimento das próprias competências e qualidades como forma de garantir uma boa vaga no mercado.

A partir do momento que estou formada já sei o que eu gosto e não gosto dentro da área. Então é ir atrás de um estágio, um emprego dentro do que mais me afeiçoa para eu já poder ingressar no mercado de trabalho mesmo (Estudante escola A).

Tem que ter determinação... assim, tem que ter foco também (Estudante escola C)

Eu me acho muito novo pra decidir o que eu tenho como objetivo profissional, mas eu tenho sempre em mente que eu não posso parar de estudar, porque eu acho que, quanto mais eu me especializar, mais as portas vão se abrir pra mim (Estudante escola C)

Eu acho que é assim, no meu caso, onde eu trabalho, quem se dedica e faz o trabalho bem feito, o cara consegue uma promoção. (Estudante escola C)

Conclui-se que o futuro é retratado como um horizonte temporal provido de ser alcançado pela inerente disposição dos indivíduos em "correr atrás" de seus objetivos, a partir de uma espécie de estofo que lhe permita estar preparado para enfrentar todo tipo de adversidade e conferindo sentido para se agir no presente. Conforme compreende Leccardi (2005, p. 36, grifos da autora) "Nessa perspectiva, o futuro é o espaço para a construção de um projeto de vida e, ao mesmo tempo, para a definição de si: projetando que coisa se fará no futuro, projeta-se também, paralelamente, quem se será".

No que diz respeito às motivações, percepções e expectativas por parte dos estudantes em relação aos cursos técnicos e às instituições de ensino, o materialismo-histórico desenvolvido por Marx e Engels (2007) em "A Ideologia Alemã" oferece robusta contribuição. Primeiramente, os autores expõem que a existência humana e o modo de saciamento de suas necessidades é o pressuposto da própria história humana, pois trata-se de "[...] uma condição fundamental de toda a história, que ainda hoje, assim como há milênios, tem de ser cumprida diariamente, a cada hora, simplesmente para manter os homens vivos" (MARX; ENGELS, 2007, p. 32).

No entanto, é preciso que se ressalte, essa abordagem explicativa da vida humana reconhece que, embora humanos se façam humanos a partir dos vínculos com que estes se deparam em sua vida material, estes são sujeitos ativos no processo histórico. Ou seja, ao mesmo tempo que o ser humano depende de condições materiais postas, independentemente de sua vontade, sua capacidade de agir no decorrer da história, pode alterar a sua realidade, gerando então, novas condições de vida.

O modo pelo qual os homens produzem seus meios de vida depende, antes de tudo, da própria constituição dos meios de vida já encontrados e que eles têm de reproduzir. Esse modo de produção não deve ser considerado meramente sob o aspecto de ser a reprodução da existência física dos indivíduos. Ele é, muito mais, uma forma determinada de sua atividade, uma forma determinada de exteriorizar sua vida, um determinado modo de vida desses indivíduos. Tal como os indivíduos exteriorizam sua vida, assim são eles. O que eles são coincide, pois, com sua produção, tanto com o que produzem como também com o modo como produzem. O que os indivíduos são, portanto, depende das condições materiais de sua produção (MARX; ENGELS, 2007, p.88, grifos da edição).

A fundamentação sobre o indivíduo, portanto, não o compreende como um mero efeito das determinações econômicas, mas como parte de um processo de formação humana em que não há sujeito sem objeto e vice-versa, ou seja, ao mesmo tempo em que as condições materiais imediatas forjam a objetivação da vida humana, esta, por sua vez, possibilita formas de subjetivação. Trata-se de um 
empenho de Marx e Engels em elucidar que a construção da subjetividade que se expressa na consciência é construída socialmente, em uma determinada formação social e consequente tempo histórico, pois "A vida é essencialmente prática" (tese oitava sobre Feuerbach). A consciência, portanto, seria construída com base nas circunstâncias vivenciadas pelos indivíduos e não como uma atividade isolada.

Os homens são os produtores de suas representações, de suas ideias e assim por diante, mas os homens reais, ativos, tal como são condicionados por um determinado desenvolvimento de suas forças produtivas e pelo intercâmbio que a ele corresponde, até chegar às suas formações mais desenvolvidas. A consciência [Bewusstsein] não pode jamais ser outra coisa do que o ser consciente [bewusste Sein], e o ser dos homens é o seu processo de vida real (MARX; ENGELS, 2007, p.94).

Nesse caso, Marx e Engels compreendem que expressões da subjetividade comumente relacionados à individualidade do ser humano, tais como vontade, aptidão, esforço, dom não se explicam por uma essência abstrata nata e que se encerra nos próprios indivíduos, mas por meio das condições materiais as quais esses indivíduos se formam enquanto seres sociais. Esse entendimento, que afasta por completo a visão de indivíduo atomizado, confere protagonismo à práxis como instância de realização da humanização do próprio ser humano.

O desenvolvimento de um indivíduo é condicionado pelo desenvolvimento de todos os outros, com os quais ele se encontra em intercurso direto ou indireto, e que as diferentes gerações de indivíduos que entram em relações uns com os outros possuem uma conexão entre si, que a existência física das últimas gerações depende da existência de suas predecessoras, que essas últimas gerações, recebendo das anteriores as forças produtivas e as formas de intercâmbio que foram acumuladas, são por elas determinadas em suas próprias relações mútuas. Em poucas palavras, é evidente que um desenvolvimento sucede e que a história de um indivíduo singular não pode ser de modo algum apartada da história dos indivíduos precedentes e contemporâneos, mas sim é determinada por ela (MARX; ENGELS, 2007, p. 422).

Ou seja, apoiado em Marx e Engels, defende-se que as expressões materiais da subjetividade humana, tais como vontade, o pensamento, a vocação e projeto de vida são aspectos forjados pelas relações sociais contraídas e esse conjunto de capacidades desenvolvidas e manifestadas representam a forma de envolvimento dos indivíduos com o mundo e as possibilidades de desenvolvimentos futuros.

\section{CONSIDERAÇÕES FINAIS}

No decorrer do texto, procurou-se estabelecer que a EPTNM está imersa em um campo de disputas que lhe tenta atribuir sentidos formativos e de que forma essa modalidade de educação se relaciona com a conjuntura educacional e do mundo do trabalho. Isto posto porque a educação, ao se inserir em relações sociais capitalistas, portanto, marcadamente contraditórias, carrega consigo também essa contradição, pois, se por um lado, o empresariado requer que a formação da força de trabalho esteja alinhada com seus pressupostos, recorrentemente pragmáticos a um determinado tempo histórico e a um padrão de organização da produção, o acesso ao ensino técnico qualificado também é demanda da classe trabalhadora, tanto em relação a postular uma base salarial que lhe permita a subsistência material mais confortável quanto a desfrutar do direito à educação, visando o autodesenvolvimento.

Tendo em vista a exposição do artigo, constata-se que a EPTNM teve uma expressiva expansão desde o século XXI, sobretudo a partir de 2007, com a retomada do investimento do governo federal na construção de unidades de ensino e campus dos Institutos Federais, bem como a miríade de ações e programas no sentido de alçar a EPTNM como eixo para sustentar a manutenção da retomada do desenvolvimento econômico. No entanto, a expansão da EPTNM e da própria constituição da Rede Federal de Educação Profissional, Científica e Tecnológica esbarrou em fatores estruturais próprias do capitalismo brasileiro. Embora as frações da classe dominante requeiram uma força de trabalho mais escolarizada, não seria necessário que a formação complexa atinja patamares tão elevados, pois o padrão de ocupações laborais ainda se sustenta com níveis de baixa e média escolarização. Desse modo, 
concomitante à expansão da EPTNM, impulsionada por instituições federais na modalidade do ensino médio integrado, também foram destinados vultosos recursos à formação em cursos de qualificação profissional promovidos por estabelecimentos privados, sobretudo ligados ao Sistema S.

Todo esse meandro a respeito da EPTNM ocorre em um contexto histórico de intensa precarização do trabalho e expropriação de direitos. O léxico discursivo engendrado por seus defensores e extensamente massificado por veículos de comunicação se apoia em um imaginário de que a flexibilização das leis trabalhistas e de reformas no funcionamento do Estado é que promoverá o expurgo da crise econômica, e, em consequência, a retomada dos empregos. Tal fraseologia sobre o mundo está baseado no fato de que as relações sociais dominantes se expressam como ideias, pois "As ideias da classe dominante são, em cada época, as ideias dominantes, isto é, a classe que é a força material dominante da sociedade é, ao mesmo tempo, sua força espiritual dominante" (MARX; ENGELS, 2007, p. 47). Portanto, são ideias que ao invés de revelar a materialidade do mundo, ocultam-nas e produzem inversões que procuram justificar o porquê de determinadas medidas seriam necessárias (por exemplo, a reforma trabalhista é posta como necessária para a retomada de empregos para a classe trabalhadora, mas serve para baixar os custos dos capitalistas com a força de trabalho).

Diante de uma conjuntura regressiva e desfavorável, buscou-se ouvir como os estudantes da EPTNM manifestam suas motivações, percepções e expectativas em relação à formação profissional e possível inserção no mundo do trabalho. Está defendido no presente texto que a consciência dos indivíduos está fortemente influenciada pelas relações materiais de produção e o lugar que nela os indivíduos ocupam. Logo suas expressões subjetivas, tais como a escolha, a vontade, a aptidão, entre outras, relacionam-se com seus meios objetivos de vida. No entanto, o ser humano como um ser social capaz de recriar e transformar seus meios de objetivação, também tem a capacidade de alterar a subjetivação com que sente e interpreta a vida. Por isso, há rejeição qualquer tipo de determinismo econômico como uma relação direta sobre a formação da consciência humana.

Os estudantes, por meio das entrevistas, identificaram e alguns até valorizaram a influência da família sobre suas escolhas e destinos; julgaram os limites e possibilidades dos processos formativos aos quais estão submetidos; interpretaram que a crise do capital lhes traz dificuldades concretas para o tempo presente e em qualquer tipo de projeção futura, o que também é parte do processo de autoformação de indivíduos que estão em uma espécie de rito de passagem para a vida adulta; e, mesmo em meio às dificuldades impostas por situações além do seu controle direto, acreditam que podem recorrer a estratégias para superá-las. Essa breve síntese dos resultados da pesquisa de campo possibilitou pôr em evidência a elaboração dos estudantes de EPTNM acerca do seu presente e de perspectivas de projeção, o que se torna algo desafiador, tendo em vista a conjuntura histórica regressiva no mundo do trabalho e na educação. No entanto, se a incerteza e a imprevisibilidade estão patentes no tempo presente, a capacidade de recriar e de transformar dos seres humanos, sobretudo a inventividade dos mais jovens oferecem uma possibilidade de reviravolta por dias melhores.

\section{REFERÊNCIAS}

ABÍLIO, Ludmila C. Uberização do trabalho: subsunção real da viração. Blog da Boitempo, publicado em: 22 fev. 2017. Disponível em: https://blogdaboitempo.com.br/2017/02/22/uberizacaodo-trabalho-subsuncao-real-da-viracao/. Acesso em: 23 ago. 2019.

ALVES, Giovanni. Dimensões da precarização do trabalho: ensaios de Sociologia do Trabalho. Bauru: Canal 6 Editora, 2013.

ANTUNES, Ricardo. O privilégio da servidão: o novo proletariado de serviços na era digital. São Paulo: Boitempo, 2018.

BRASIL. Lei n ${ }^{\circ}$ 9.394, de 20 de dezembro de 1996. Estabelece as diretrizes e bases da educação nacional. Diário Oficial da União, Brasília, DF, 23 dez. 1996. Disponível em: http://www.planalto.gov.br/ccivil 03/leis/L9394.htm, acesso em 20 out. 2020. 
BRASIL. Decreto no 5.154, de 23 de julho de 2004. Regulamenta o $\int 2^{\circ}$ do art. 36 e os arts. 39 a 41 da Lei $n^{\circ}$ 9.394, de 20 de dezembro de 1996, que estabelece as diretrizes e bases da educação nacional, e dá outras providências. Diário Oficial da União: Brasília, DF, 2004, 26 jul. 2004. Disponível em http://www.planalto.gov.br/ccivil 03/ ato2004-2006/2004/decreto/d5154.htm. Acesso em: 20 out. 2020.

BRASIL. Lei $\mathrm{n}^{\circ}$ 11.741, de 16 de julho de 2008. Altera dispositivos da Lei no 9.394, de 20 de dezembro de 1996, que estabelece as diretrizes e bases da educação nacional, para redimensionar, institucionalizar e integrar as ações da educação profissional técnica de nível médio, da educação de jovens e adultos e da educação profissional e tecnológica. Diário Oficial da União: Brasília, DF, 17 jul. 2008. Disponivel em: http://www.planalto.gov.br/ccivil 03/ ato2007-2010/2008/lei/111741.htm. Acesso em: 20 out. 2020.

BOLSONARO, Jair. Com a palavra [Entrevista a Leda Nagle]. Publicado em: 5 ago. 2019. Disponível em: https://www.youtube.com/watch?v=VLLxBxN87ZE. Acesso em: 22 ago. 2019.

BOURDIEU, Pierre. A escola conservadora: as desigualdades frente à escola e à cultura. In: NOGUEIRA, M. A; CATANI, A (orgs.). Escritos de educação. 16 ed. Petrópolis: Vozes, 2015, p. 43-72.

BRASIL. Lei no 13.005, de 25 de junho de 2014. Aprova o Plano Nacional de Educação - PNE e dá outras providências. Diário Oficial da União: seção 1, edição extra, Brasília, DF, 26 jun. 2014. Disponível em: https://www2.camara.leg.br/legin/fed/lei/2014/lei-13005-25-junho-2014-778970_ publicacaooriginal-144468-pl.html. Acesso em: 30 mar. 2020.

BRASIL. Instituto Nacional de Estudos e Pesquisas Educacionais Anísio Teixeira. Relatório do $2^{\mathbf{o}}$ ciclo de monitoramento das metas do PNE: biênio 2016-2018. Brasília: INEP, 2018.

CAIRES, Vanessa.; OLIVEIRA, Maria Aparecida. Educação Profissional brasileira: da Colônia ao PNE 2014-2024. Petrópolis: Vozes, 2016.

CASSIOLATO, Maria Martha; GARCIA, Ronaldo. Pronatec: múltiplos arranjos e ações para ampliar o acesso à educação profissional. Brasília, Rio de Janeiro: IPEA, 2014.

COSTA, Fernanda. A execução orçamentária do Programa Nacional de Acesso ao Ensino Técnico e Emprego (Pronatec) entre 2011 e 2014. In: Marx e Marxismo 2015: insurreições, passado e presente, 2015, Niterói. Anais..., Niterói, 2015.

CARNEIRO, Moaci. LDB fácil: leitura crítico-compreensiva, artigo a artigo. 23 ed. Petrópolis: Vozes, 2015.

CORREA, Licinia; CUNHA, Maria Amália. A política educativa e seus efeitos nos tempos e espaços escolares: a reinvenção do ensino médio interpretada pelos jovens. Educação em Revista, Belo Horizonte, n. 34, e182749, 2018.

DEITOS, Roberto.; LARA, Angela. Educação profissional no Brasil: motivos socioeconômicos e ideológicos da política educacional. Revista Brasileira de Educação, v. 21, n. 64, p. 165-188, jan./mar. 2016.

FONTES, Virgínia. O Brasil e o capital-imperialismo: teoria e história. Rio de Janeiro: ESPJV, UFRJ, 2010. 
GOMES, Alberto. Apontamentos sobre a pesquisa em educação: usos e possibilidades do grupo focal. Eccos, São Paulo, v. 7, n. 2, p. 275-290, jul./dez. 2005.

IBGE. Instituto Brasileiro de Geografia e Estatística. Pesquisa Nacional por Amostra de Domicílios Contínua - Segundo trimestre de 2019. Disponível em: https://biblioteca.ibge.gov.br/visualizacao/periodicos/2421/pnact 2019 2tri.pdf, acesso em 23 ago. 2019.

INEP. Instituto Nacional de Estudos e Pesquisas Educacionais Anísio Teixeira. Sinopse Estatística da Educação Básica. Brasília, DF: INEP, 2003. Disponível em: http://inep.gov.br/sinopsesestatisticas-da-educacao-basica. Acesso em: 16 set. 2019.

INEP. Instituto Nacional de Estudos e Pesquisas Educacionais Anísio Teixeira. Sinopse Estatística da Educação Básica. Brasília, DF: INEP, 2008. Disponível em: http://inep.gov.br/sinopsesestatisticas-da-educacao-basica. Acesso em: 16 set. 2019.

INEP. Instituto Nacional de Estudos e Pesquisas Educacionais Anísio Teixeira. Sinopse Estatística da Educação Básica. Brasília, DF: INEP, 2019. Disponível em: http://inep.gov.br/sinopsesestatisticas-da-educacao-basica. Acesso em: 16 set. 2019.

LEÃO, Geraldo; DAYRELL, Juarez; REIS, Juliana. Juventude, projetos de vida e ensino médio. Educação e Sociedade, Campinas, v. 32, n. 117, p. 1067-1084, out./dez. 2011.

LECCARDI, Carmen. Por um novo significado do futuro: mudança social, jovens e tempo. Tempo Social, São Paulo, v. 17, n. 2, p. 35-57, nov. 2005.

MARCASSA, Luciana; CONDE, Soraya. Juventude, trabalho e escola em territórios de precariedade social. In: Reunião Nacional da Associação Nacional de Pesquisa em Pós-Graduação em Educação, 38, 2017, São Luís. Anais [...]. Rio de Janeiro: ANPEd, 2017.

MARX, Karl; ENGELS, Friedrich. A Ideologia alemã. São Paulo: Boitempo, 2007.

MOTTA, Vânia; FRIGOTTO, Gaudêncio. Por que a urgência da Reforma do Ensino Médio? Medida Provisória no 746/2016. Lei no 13.415/2017. Educação e Sociedade, Campinas, v. 38, n. 139, p. 355372, abr./jun. 2017.

MOTTA, Vânia; LEHER, Roberto; GAWRYSZEWSKI, Bruno. A pedagogia do capital e o sentido das resistências da classe trabalhadora. Ser Social, n. 43, p. 310-328, jul./dez. 2018.

NOGUEIRA, Cláudio; RESENDE, Tânia; VIANA, Maria José. Escolha do estabelecimento de ensino, mobilização familiar e desempenho escolar. Revista Brasileira de Educação, v. 20. n. 62, p. 749-772, jul./set. 2015.

OCDE. ORGANIZAÇÃO PARA A COOPERAÇÃO E DESENVOLVIMENTO ECONÔMICO. Education at a Glance 2018: OECD Indicators. Paris: OCDE, 2018. Disponível em: http://download.inep.gov.br/acoes internacionais/eag/documentos/2018/EAG Relatorio na integr a.pdf. Acesso em: 22 ago. 2019.

SANTOS, Jailson; RODRIGUES, José. (Des) Caminhos da política de expansão da Rede Federal de Educação Profissional, Científica e Tecnológica: contradições na trajetória histórica. Marx e o Marxismo, Niterói, v.3, n.4, p.88-112, jan/jun.2015. 
Submetido: 12/07/2019

Aprovado: 02/10/2020 